\title{
Towards professional responsibility for language and literacy: exploring vocational teachers' emerging language and literacy understandings and identities
}

\section{TAO BAK and PAULINE O'MALEY}

\begin{abstract}
The role of vocational teachers is complex and evolving (Moodie \& Wheelahan 2012). The imperative to also attend to students' language literacy and numeracy (LLN) skills adds to this complexity. Using data from interviews with eight teachers, this paper explores this emergent space in relation to impacts on their sense of capacity and confidence to attend to LLN, and ways this is being incorporated into a renewed, but often still fragile sense of professional identity (Brookfield 2000). Where the focus of discussion is often on LLN requirements, we concentrate here on the perceptions and experiences of the teachers themselves, and how these insights may inform our approach as LLN specialists. We conclude that vocational teachers appear willing travellers on this journey, but often feel they have a distance to go. We make a case for a collaborative dialogic approach to this shared challenge.
\end{abstract}

\section{Introduction}

Vocational teachers and trainers in Australia, like their counterparts in the UK, have in recent years increasingly been asked to add addressing the language, literacy and numeracy (LLN) skills of their students to their collection of professional responsibilities. In terms of its sheer range of disciplines and specialisations the field of vocational education and training (VET) in Australia has been characterised as fragmented and diverse (Moodie and Wheelahan 2012). In such a context, this requirement can be seen to represent an important new strand of responsibility for an already notably complex 
role and identity for VET teachers. VET teachers are compelled to grapple not only with the implications of the pedagogical and philosophical 'divide' between teaching and training (Santoro 2003, Wheelahan 2009), but with the complexities of the dual 'industry' and 'teacher' identities at play within their professional roles and work (Seddon 2008). In addition to this, in LLN provision within VET in Australia, and in particular 'integrated' LLN in VET courses, there has been 'no uniform model' across the states and territories (Black \& Yasukawa 2013:46).

Whilst there is little disagreement regarding the need for a more comprehensive approach to LLN development and support within vocational education (VE) in Australia, along with the consideration of mechanisms to enable this to occur (Industry Skills Councils 2011, Skills Australia 2011, Australian Industry Group 2010), there has been minimal focus on how vocational teachers themselves are responding to this new professional imperative. An understanding of the experiences and perceptions of practitioners and an informed sense of the nature of the challenges involved provide possibilities for enabling a smoother transition into this new space. This knowledge is important not least because where there is a lack of connection between higher level aims and on-the ground practicalities, the potential for resistance to perceived 'top-down' impositions often undermine the more well-meaning intentions of the broader agendas at play. Indeed, as Chappell, Scheeres and Solomon (2007:167) point out, changes at the organisational macro level can often overshadow the micro level processes that 'simultaneously constitute and are constituted by such macro changes'.

In terms of a focus on language and literacy support and development in vocational and further education contexts, there has been an extensive and thorough examination of literacy practices in further education in the UK which broadens the theoretical framing of literacy in the context of improving student learning (Ivanič, Edwards, Barton, Martin-Jones, Fowler, Hughes, Mannion, Miller, Satchwell \& Smith 2009). In Australia, Black and Yasukawa (2011, 2013 a \& b) have researched the integration of LLN in VET courses, examining, amongst other things, various models of integration, the implications of these on the professional relationships between VET teaching and specialist LLN staff, and foregrounding the significance of these relationships. This paper builds on this work with a specific focus on the response of VET teachers to the imperative of 
themselves becoming a locus for LLN, and on what these responses suggest regarding the nature of the challenge that taking up this responsibility represents, particularly in terms of the implications of a movement towards a (more) expert view of language and literacy itself. Specifically, this paper reports on an exploratory study examining the views of a small group of teachers from a Technical and Further Education (TAFE) program within a dual sector institution in Australia. This research, both in response to the support needs of the specific VET teachers represented here, and in keeping with the expertise and practice of the researchers themselves, focuses particularly on the language and literacy, rather than numeracy responsibilities these VET teachers were taking up.

The data for this study comes from qualitative interviews with teachers who had all participated in an in-house professional development workshop series focussing on understanding and addressing the language and literacy needs of students, an initiative that coincided with a concerted increase in focus on LLN across the whole institution. In reflecting on the insights this examination of teacher perceptions offers in regards to the process of taking up this new professional responsibility, not only will we draw on the perceptions of the teachers themselves, but on our own views and experiences as language specialists with extensive experience of working with VET teachers in this space. A secondary focus of the paper therefore is to reflect on this new 'sharing of a professional domain' for language and literacy specialists, and the implications of this for VET teachers' own professional relationships and understandings. Ultimately the paper contends that the adjustment to the VET teachers' role calls for the uptake of new forms of professional practice and identity (Chappell et al 2007), including a newly cast collaborative relationship with language specialists.

\section{Theoretical literature framing the study}

In exploring the shifting and emergent 'professional' understandings of language and literacy that are evident in the interview data that we will present, we will draw on a number of theoretical concepts. These will include the notions of discourse and identity (Gee 1996, Ivanič 1998), and the notions of 'troublesome knowledge' (Meyer \&Land 2006) and 'threshold concepts' (Land, Meyer \& Smith 2008). 
Gee's (1996) work on Discourse (which he signifies with a capital D to distinguish it from discourse as a unit of connected speech) illustrates the significance of discursive positioning, and the way in which it is entwined with identity. He suggests

Discourses ... are ways of behaving, interacting, valuing, thinking, believing, speaking, and often reading and writing that are instantiations of particular roles by specific groups of people ...Discourses are ways of being 'people like us'. They are 'ways of being in the world'; they are 'forms of life' (Gee 1996: viii).

This understanding of Discourse, not just a way of using language but as a way of being, opens up a way of seeing how the teachers are positioning themselves discursively in this new space, and to what extent this new aspect of their identity is becoming a 'way of being in the world' for them.

Although a more cognitive concept, we suggest that the notion of threshold concepts can also be fruitfully applied in this case to afford an insight into the process of vocational teachers' movement towards acquiring an 'expert' view of language itself. Threshold concepts (Meyer \& Land 2006) refer to key concepts to learn that are troublesome but that can transform a novice learner into a discipline expert. More specifically, threshold concepts have been defined as having the characteristics of being transformative, integrative, bounded, troublesome, and perhaps irreversible. They open up 'new and previously inaccessible ways of thinking about something' (Meyer \& Land 2003:1). Examples of threshold concepts are the concept of 'signification' from cultural and literary studies for example, or 'opportunity cost' from economics. The process of understanding these concepts represents movement on the continuum from novice to expert. For vocational teachers, the move to integrate at least some responsibility for language and literacy into their list of professional duties, we argue, implies a need to engage with the notions of language and literacy conceptually.

These concepts to us, as language and literacy specialists working with tertiary teachers and lecturers, have proven to be useful in providing a lens into the partial, fluid, and at times dissonant conceptual process or journey that these teachers are undertaking.

\section{The context for the study}


The imperatives for an increased and dispersed responsibility for LLN within vocational education in Australia are numerous. They include the generally low language literacy numeracy rates within Australian society (Industry Skills Councils 2011) as indicated by mass surveys like the International Adult literacy Survey (IALS), and the Adult Literacy and Lifeskills Survey (ALL), and more recently the Programme for International Assessment of Adult Competencies (PIACC), which consistently indicate the alarming, much quoted statistic that approximately half of Australian workers do not have the literacy and numeracy skills necessary to work in the knowledge society. While there is critique of the particular and partial nature of these surveys (Hamilton \& Barton 2000), not to mention the crises narrative that they generate (Ivanič et al 2009), they have received significant attention and have had a powerful impact, resulting in a focussed imperative for LLN to be foregrounded in the vocational education curriculum, as well as the responsibility for LLN to be taken up 'across the board' within the vocational education landscape. Mechanisms to facilitate this uptake include the mapping of 'foundation skills' - the new term used in Australian VET policy to refer to what has traditionally been referred to as English language, literacy and numeracy, into curricula, as well as the development of a new training package for foundation skills. In the Australian VET/further education context, core foundation skills are outlined in the five level, five skills (reading, writing, oral communication, numeracy and learning) national assessment framework known as the Australian Core Skills Framework (ACSF), which is complemented by the outline of key employability skills in the Core Skills for Work (CSFW) framework. Together these provide a basis for the Foundation Skills Training Package set of units, in accordance with the competency based national training curriculum system for VET/further education in Australia. In addition, the previously elective unit 'Address Adult Language, Literacy and Numeracy Skills', has been designated a core unit in the entry-level vocational teacher qualification, the Certificate IV in Training and Assessment from 2014 (Innovations \& Business Skills Australia [IBSA] 2012). Within this context, state governments in Australia are placing increasing scrutiny on what institutions are doing to identify and then to respond to the LLN needs of their students.

Whilst moves to include responsibility for LLN more explicitly within the direct scope of the vocational teacher's work in Australia 
are still at a relatively early stage, pre-training LLN assessment has now become mandatory. Likewise, strategies and policies to embed LLN support and development across courses and programs in a more coherent and systematic fashion are subject to audit also. In short, it is clear that LLN is no longer the concern of the LLN specialists alone, with the responsibility increasingly falling to the VET teachers themselves. This paper will focus on the perceptions of these VET teachers from one institution in regards to these developments.

\section{The study}

The study included eight participants from a range of disciplines at Certificate IV and Diploma level, including health administration, information technology, community services, disability and community services, business, and commercial cookery. Most participants have more than five years of experience in VE, and all were drawn from attendees of a two-workshop professional development program, the first of which centred on understanding the ACSF, and the second on applying the ACSF to better meet the language and literacy needs of students. Invitations to participate in the study were sent to potential participants within two months of having attended. The interviews were semi-structured, approximately an hour in length, and focused on perceptions of language and literacy in the classroom. In addition to the background and experience of the teacher, topics or themes covered included whether and to what extent language and literacy was an issue in their classroom, the sense of capacity they felt to address these issues, the extent to and ways in which they felt supported by the broader institution in addressing these issues, and whose ultimate responsibility they felt it was to address the language and literacy needs of students. The interviews were audio recorded and transcribed for analysis in regards to key themes and perceptions.

The workshops participants had attended were facilitated as part of an institution-wide strategy to facilitate a more strategic and coordinated approach to language and literacy across all sections of the dual-sector institution (Curró 2012). The workshops attracted approximately 130 attendees overall. Although the workshop series was practically oriented, it was underpinned by a developmental academic literacies model which 'views the process involved in acquiring appropriate and effective uses of literacy as ... complex, dynamic, nuanced, situated, and involving both epistemological 
issues and social processes' (Lea \& Street 2006:269). The concept of 'embedding' language and literacy, reflecting the 'built in, not bolted on' (Wignall 1998) approach, was emphasised, and whilst there are different interpretations about what embedded means in practice (Arkoudis 2013), the different approaches share the notion of bringing together content teaching and LLN teaching (Casey, Cara, Eldred, Grief, Hodge, Ivanič, Jupp, Lopez, \& McNeil 2006, Roberts, Baynham, Shrubshall, Brittan, Cooper, Gidley, Windsor, Eldred, Castillino, \& Walsh 2005). Further, they display specific shared features, some structural and some attitudinal, which include team work; shared understandings, values and beliefs; aspects of teaching and learning that connect LLN explicitly with discipline content; enabling policies and organisational features at institutional level (Casey et al 2006). The notion that the vocational teachers are the experts on what counts as the appropriate language and literacy within their discipline or industry area, even though this knowledge may be tacit and not always able to be articulated, was also explicitly foregrounded. The facilitators of the workshops, themselves language and literacy specialists, were aware that they approach particular discipline discourses as outsiders, and noted the importance of acknowledging the insider-status of the vocational teachers in this regard, as well as acknowledging the advantages of 'seeing' a discipline through the eyes of an outsider (Jacobs 2007).

Whilst the primary aim of the study was to capture the perceptions of VET teachers regarding the challenges relating to language and literacy generally, there was an additional interest in how the teachers were responding to the approach to building capacity and conceptual understanding regarding language and literacy represented by the workshops they had attended. Given the limited number of teachers interviewed, the contribution of the study is intended as exploratory, and limited to the possibility of raising themes for potential further study. It is acknowledged that the teachers who responded to the invitation to participate in the study may have been those interested in or favourably disposed towards understanding and acting to address language and literacy issues within their classrooms. An additional limitation of the study is that it included mainly teachers from para-professional disciplines, rather than trades or further studies areas. This is one reason we use the terminology 'teacher' throughout, although we acknowledge that the term 'trainer' is preferred by some VET teachers (Moodie \& 
Wheelahan 2012). Whilst the discussion below acknowledges the language and literacy specialist perspective, primarily through the views of the authors, the study does not attempt to capture the experiences of LLN specialists; its focus is specifically on the perceptions of the vocational teachers.

\section{Overall findings}

In terms of overall findings almost all of the participants felt that language and literacy was a significant challenge for their students, and the majority reported an increase in language and literacy related issues in recent years. Most participants reported the language and literacy needs of their students as having an impact on their teaching, with only one reporting no significant impact. The main factor cited relating to this was the impact on time, which included the need for more time in class to cover set topics, as well as the additional planning time to cater for disparate language levels within a particular group. This is a factor likely exacerbated by the diminishing resources devoted to VET in Australia, which have increased the pressure of time for vocational teachers. Participants reported mixed levels of confidence in their capacity to meet the language and literacy needs of their students. Generally confidence was fairly low, with some feeling under qualified, and others reporting constraints such as the impact of low attendance rates (seen as a related issue) and grappling with the necessities of, or perceived pressure to accept, lower quality work. Or, alternatively, of being unclear as to what level of work was acceptable. In regards to this last issue, the five levels offered by the ACSF were seen by almost all of the respondents as helpful in facilitating more confidence in their judgments in regards not only to the language and literacy performance of their students, but of the language and literacy requirement of the units or courses they were teaching.

Indeed, most participants felt the workshops they had attended were valuable, particularly as an opportunity to focus on issues relating to language and literacy in a dedicated way and to improve their understanding of these issues. When asked whose responsibility they felt language and literacy was, almost all of the participants suggested that they needed to be a shared responsibility, although they differed in who this extended to, citing the teacher themselves, the school or department, the LLN support team, the students themselves and, in one case, the students' parents. One teacher with a 
dissenting view felt the responsibility was shifting and that it was now primarily the teachers', adding, that he thought teachers were 'willing to take that responsibility'. Several participants mentioned the need for a collaborative approach, or as one participant put it, 'it needs to be a team approach... and it needs to be really cohesive'.

Whilst there was general agreement in regards to the need for shared responsibility, there was less certainty in regards to how this responsibility might be enacted in the classroom or the curriculum. Otherwise put, there was a clear willingness to be involved, but, perhaps not surprisingly, less confidence or consistency of view in regards to what this might mean in actual practice. It is some of the intricacies involved in this question that we wish spend the rest of this paper focussing on.

\section{A complex journey}

In looking more closely at the complexities at play for vocational teachers in taking up responsibility for language and literacy, both in terms of developing and shifting their understandings of language and literacy and the processes that this may involve, we begin with a somewhat extended quote from one of the participants.

I don't want him to go away. I want him here. It is something I can improve, and how I can work with these guys? I don't like the idea of your English is not great so you can't do the course. Because I know in practice, they're going to be exceptional... I've had people in the workplace who are exceptional. You can't assess passion and you can't assess commitment. They're exceptional, but what lets them down? They struggle with the written component. So we modified it, so they get through. 'Cause they're going to get themselves a job, and they're going to be beautiful in their job.

Although at first glance this statement appears a little fragmented, we came back to it in the conviction that it, in fact, works effectively to reflect some of the competing tensions and imperatives with which vocational teachers are increasingly expected to grapple. The quote encapsulates several prominent threads of the teacher discourses around their students' specific contextualised needs; their own understanding of industry, and the complex factors, some educational and some personal, that they believe make for successful workers; and it also highlights the ways in which these teachers are positively oriented towards their students and their needs. It gives us 
an insight into how this teacher, in a similar way to the others in our study, locates and identifies herself. The teachers in this sample have a wealth of industry experience and their confidence in their industry knowledge shines through. For the most part they position themselves discursively from an industry perspective. This accords with Ivanič's (1998) notion that we tend to position ourselves in response to discourses we have access to and those we privilege, and is reinforced by their lack of confidence about their educational identities, for the most part. Futhermore, they demonstrate they are unsure of their teacherly identity in relation to language and literacy. In this regard some even position themselves as what Brookfield (2000) might call 'imposters' in this space. Their identity as 'teachers', as we can see in the data below, is complex, fluid, and sometimes contradictory. This way of locating and identifying themselves gives us insight into these conflicted 'ways of being in the world' (Gee 1996).

In this context, the challenge for vocational teachers in taking up responsibility for language and literacy is naturally, to gain confidence in positioning themselves discursively in this space; it needs to become part of a way of being in the world for them. The wealth of industry experience serves these vocational teachers well in giving them insights into the imperatives from both sides, industry and the institutional, yet their discomfort in foregrounding their role as educators, perhaps not surprisingly, remains.

There's no requirement for me to have an education background. In fact it's not needed at all in TAFE. But it kind of is, isn't it?

It kind of is! And this is the complex, often contradictory, sometimes uncomfortable, ever changing space the vocational teacher is asked to take up. It is further compounded when students' language and literacy needs are factored in; yet this is the space that calls to be confidently inhabited in the future work of vocational teachers. Their students' success depends on it.

\section{How did the teachers position themselves in regards to the challenge of language and literacy?}

That there had been an increase in language and literacy needs within student cohorts over time was a fairly consistent observation amongst the participants. Some explicitly stated that these changes often bring students for whom English is not their first, or even second or third, language to the classroom and that this is often 
complicated by these students having disrupted education and often leaving school early, sometimes as early as the end of year nine. As one participant stated, 'they can do the work. They've got the aptitude, they've got the passion for it, but it's hard. It's a harder gig for them'.

In the data a tension was evident in the responses between flexibly responding to these new cohorts as they are, and the rather inflexible need to get the 'level' just right to align to the standard, informed in the first instance with an eye on the future workplace they imagine their students to be in. They indicated this has impact not only on the work they can do but also on the pressure of time they feel. Accounting for language and literacy adds to this pressure. Despite the challenges of changing cohorts, uncertain times and top down strategies, however, our interviews reflected teachers who are open both to the notion that language and literacy needs to be part of their classroom picture and the acknowledgement that they have some responsibility themselves for addressing the language and literacy needs of the students. Indeed one participant suggested while it was a massive challenge, it was a challenge she embraced, stating that 'I guess it's a massive challenge for me ... I embrace a challenge like that, I actually think it's fantastic to have these students'.

This openness to some extent surprised us as researchers, as we were aware of the potential burden this places on vocational teachers and also of the challenges of shifting responsibilities where these have not necessarily existed historically. We felt this openness resulted from their lived experience of working with their richly diverse student cohorts. The teachers appeared particularly well attuned to their students, their capabilities and the barriers they face. As one teacher put it in regards to her course assignment, 'that is hard for English as your first language, let alone your third'. We saw this as significant in that this genuine empathy for, and appreciation of, the students seemed to underpin a positive alignment with the language and literacy 'challenge'.

Despite the general positive alignment however, the teachers in the study expressed clear differences in their sense of capacity in relation to language and literacy. Two of the teachers in the sample identified themselves in a positive way in relation to language and literacy. 
I'm very interested in language ...I'm a linguaphile of the old style. I suppose I enjoy language, it is a wonderful thing, for me it is very expressive.

My background was not in literacy and numeracy but... I was successfully inducted into the Language Development Unit [when I started here] ...

On the other hand, other teachers articulated distinctly negative conceptions of themselves in relation to literacy and numeracy.

To be honest with you I used to be quite intimidated when I didn't have a writing teacher in the class and it was my job to, you know, to help people with writing. Because I actually struggle with writing myself...I'm probably not that bad, but I don't like it very much.

Or as another teacher put it,

$L L \& N$ is something I'm not strong in. I mean, even for my own

... I'm not strong in it. It never has been [a strength] ... I sit there killing myself laughing. Me of all people teaching ESL!

The data indicated the teachers' confidence in their literate selves seemed to carry over into the ways in which they conceptualised literacy, ways that are partial and at times contradictory. Teachers foregrounded literacy in particular ways, depending on their background, experience and confidence. Each of them appeared to conceptualise language and literacy, perhaps not surprisingly, through the filter of their own personal industry and classroom experience. This appeared to lead to understandings of language and literacy often with a focus on particular skills in isolation. For example, one conceived it as primarily about speaking, another talked primarily about it as reading, and another focused particularly on writing. The indications were these conceptualisations were born out of their lived experiences in classrooms and their own level of comfort and confidence, yet these conceptualisations have consequences for their work with students in the classroom. While foregrounding aspects of language and literacy students will need in the workplace is both legitimate and fruitful, and moves beyond the commonly invisible or marginalised treatment reserved for 'communicative elements' in discourses of learning (Ivanič et al 2009:18), an argument could be made that moving to a more professionalised view of language and literacy support and development calls for a broader and more nuanced conception of language than may have been appropriate or adequate for the task of 
the vocational teacher historically. This is not to suggest language and literacy are not themselves contested concepts.

Murray (2010) has suggested in relation to higher education, for example, that there needs to be a clearer distinction between notions of proficiency, academic literacies, and professional communication. Similarly within vocational education there is often a lack of distinction between approaches to language and literacy informed by the Second Language Acquisition (SLA), English as an Additional Language (EAL) and adult education (AE) fields, each with particular concerns and conceptions. This opaqueness is overlain by the implications for language and literacy of the dominant competency based training (CBT) approach to education and training (Wheelahan 2009), which can be seen to favour a view of literacy as characterised by a 'set of itemised skills which students have to learn and which are then transferable to other contexts' (Lea \& Street cited in Murray 2010:59).

In terms of pedagogical attempts to respond to the language and literacy needs of their students, all of the teachers reported adapting their practice to try to 'pitch' to where they perceive the students to be at. Most commonly this included strategies such as slowing down their speech and taking care when using 'industry speak' that students may not be familiar with. Other strategies included using a wiki to ensure students engage and as a way to encourage students to develop their own voice. There was an uncertainty, nevertheless, about how to build on these often innovative strategies.

\section{Embedding language and literacy support - what does it mean?}

As mentioned above, the teachers in this study embrace the notion that language and literacy is 'everybody's business' and displayed an eagerness to find out how they could develop their skills and work collaboratively with language and literacy staff to enhance the students' experience. Yet despite their openness to, and understanding of, language and literacy as an essential part of the students' repertoire for the workplace, the teachers, for the most part, tended to talk about content and skills as discrete and literacy support as something that happens elsewhere.

... but if I need help I definitely ask for it and refer them on.

...there is concurrent assistance or somebody over there that can help you. 
Notably the teachers who expressed confidence in their understanding of the deep relationship between their content and the students' LLN developmental needs expressed at the same time firm views about the need to delineate content and skills work.

I think the mixing up, the incorporating LL\&N activities in the, in an academic skills subject, sometimes in fact, is sort of selfdefeating. ... Because the deficiencies in fact are so profound that they really have a lot to catch up on. So they're doing two things at once.

And as another stated,

I would probably be quite willing to have concurrent assistance or LLN assistance to come in as dedicated half hour within the three-hour class. This is a half hour time that is dedicated to improving your communication skills, language skills etc. To have it happen within the context of trying to get across an accounting message I think is too distracting.

It is clear to us that the teachers in this study do not tend to conceive of language and literacy as an integral aspect of the curriculum they are delivering. However, this dominant view of LLN as something that happens 'over there' sits in tension with an evolving sense, in the teachers' talk, of an emerging developmental approach in which they situate language and literacy as an integral element of the professional discourses students are being apprenticed into. For example one of the teachers who would refer students on suggests

... instead of just identifying the ones that are having difficulty,

I like to also then put together something that I think would identify all the students and put them together in one space.

Another says

I want to know if people are engaged in this process [of working with the discipline content], which is surrounded by that stuff writing and reading.

Even the teacher quoted earlier who asserted very clearly that the oil of content and the water of LLN don't mix, suggested a little later:

... opportunities- just having them for the six months is an opportunity. It's making sure that all teachers at least embed within their practice understanding of the levels of language and numeracy, and do something about it within the class. [Emphasis added] 
In our experience, the recognition that for students to develop professional language and literacy capabilities they need language and literacy to be scaffolded inside the curriculum in an explicit way (Murray 2010) is often seen as significant by language specialists. Nevertheless, this dissonance in the teachers' conceptualisations, as Wallace (2010) identifies, is part of the process of acquiring 'troublesome knowledge'. It is in these disjunctions that he suggests learning may occur. What we see here is the teachers' emergent alternative conceptions of what language and literacy could be. We know this can be an uncomfortable and unstable space that is exemplified by teachers 'oscillating between previous and emerging understandings' (Wallace 2010:12).

These emerging understandings appear to be an indicator of the evolution of a new discursive identity, characterised in this case also by the felt imperative to be embedding LLN into content and assessment, and a lack of clarity about what embedding actually involves. As one teacher expressed it, 'one particular thing that I am still not sure is how do you embed that [...] in your assessment'. And another posed the question: 'even if it's a few subjects how do we utilise the LLN component?'. These queries represent fruitful ground in which to develop partnerships with LLN staff around inclusive, developmental ways of embedding LLN into content. The teachers at the same time appeared clear that this needs to be collaborative work, one suggesting, understandably, that she felt ill-equipped to do it alone.

\section{A dialogic approach}

As suggested above, the process of foregrounding language and literacy within both curriculum and pedagogy cannot be simply linear and one-dimensional. Given the complex nature of language and literacy, its interconnectedness with content, and the diversity of student language and literacy needs, embedding and attending more explicitly to language and literacy within vocational teaching will involve a range of approaches, concepts, strategies and practices attenuated to particular cohorts in particular ways. Collaborative work with language and literacy specialists will be key in this, as ways forward are explored and developed together. The following section of this paper outlines some of the factors we feel are relevant to a generative approach to an integrated understanding and approach to language and literacy within vocational teaching. 
One of the interviewees, who teaches accounting, made a number of comments that struck us as providing one possible fruitful place to take up the next part of the conversation. What is demonstrated in this account, and we acknowledge that it is only partially reproduced here, is not just a clear picture of where the collaborative work could be taken up, but also the discursive disjunctions that are, in Wallace's (2010) terms, a space where learning, for us all, can occur. We are interested in working in the space this disjuncture opens up.

The teacher has a personal interest in language, his eye is on the big, industry focused, picture and his broad-based conceptualisation of accounting is passionately articulated. He suggests

... it is not the numbers... but understanding what the thing means, understanding what the figures mean, the story, being able to tell the story is far more important. Because the computer will spit out numbers, numbers is not the problem, understanding numbers is the problem.

This way of conceiving the 'story of accounting' opens up the opportunity for a collaborative conversation about the language and literacy aspects of this accounting story. Indeed the teacher readily focuses in on some of these aspects, such as talking on the phone, writing reports, taking and writing up minutes of meetings, and presenting, now to the class, but later 'to the board of directors'! Here is the contextualised work that can be scaffolded. Together the content teacher and the language and literacy teacher can discuss and plan how students' report writing abilities can be supported and developed, to use but one example. Students could benefit from explicit conversations about the purpose of report writing, different types of reports, the generic features of reports and the formal and profession-specific language of the reports they will need to read and write in the accounting workplace. They could benefit from such strategies as working with models of reports, taking them apart, putting them back together, critiquing them, rewriting them, identifying aspects of their structure, and many other approaches to working with and creating these texts that will become evident naturally as the specific needs of the particular cohort emerge.

So it appears to us that the next part of the journey reveals itself; however, the teacher still sees content and language and literacy as discrete, and this represents a disjunction. He suggests if a teacher were to come to his classroom he could say explicitly to the 
students, 'Righto we've finished accounting at the moment, we're now going to have a real good look at LLN stuff'.

This is the space in which to start the collaborative work and it signals to us the importance of the first part of the work being at the conversation level outside the classroom. The first task, we believe, is to have a dialogue about the language and literacy implicit within the accounting story. One approach in the scenario sketched above has been for the language and literacy teacher to bring to the conversation some appropriate materials specific to the unit, in this case perhaps models of accounting reports, some annotated to make generic features explicit. This way trust and credibility is built, and the relationship can start to evolve. Our experience tells us that as the relationship develops the teachers' 'ways of being in the world' start to shift as they begin to conceptualise language and literacy differently and change their classroom practice, to the extent that this constitutes a shift toward a new way of doing things; it can be seen as a shift towards becoming a part of a new community of practice (Wenger 1998). At the same time, as language practitioners we too find our own 'ways of being in the world' shift as this new environment and relationship impacts on our practice as we also become part of this new cross-disciplinary community of practice. The learning that takes place then, as McCormack (2014:57) has argued in relation to Academic Language and Learning (ALL) work, possesses

a dimension beyond the subject-object metaphysic of modern knowledge in which learning is simply the acquisition of additional knowledge or skill, an acquisition that does not impact on the identity of the learner.

What is called for on the part of these teachers is some shift from a lay conception of language, most likely as a relatively tangible set of items, rules or formulas (Rose 2012) to a view of language as more ineluctably bound up with content, and by extension, with ways of being, that cannot be captured by an isolated set of grammatical rules or structures alone. On this view, we suggest, the complex nature of language is itself an essential threshold concept (Meyer \& Land 2006) to be grappled with in this transformative process. This conception extends to an acknowledgement and previously unappreciated awareness that language and literacy represent dynamic, contested and contingent concepts. It moves inevitably beyond a 'naïve' single faceted view of language and literacy, and 
towards a view more in line with the multiplicities inherent in a 'literacies' view of language (Ivanič et al 2009).

In arguing for an embedded approach to language and literacy support in vocational education, Moraitis, Carr and Dadow (2012) emphasise the importance of collaborative planning and curriculum design processes for developing and sustaining pedagogies and curriculum that acknowledge the inter-relation between language and content. They point out that for many teachers 'the connection between the conceptual and the linguistic demands [of a unit or discipline] remain an unresolved area' (Moraitis et al 2012:59). In some senses, whilst on a continuum, a difference could be posited here between what vocational teachers see as language and literacy teachers supporting them in their work (more like old knowledge) and a high jump in involvement, understanding and ownership of the forms and complexity of language and literacy embedded within their domain of professional knowledge (more like new knowledge). In relation to this, Bak and Murphy (2009:198-99) argue similarly for a community of practice based collaborative approach to curriculum development, premised on the recognition that

discipline-specific language and learning skills are fundamental to the construction of meaning within particular institutional contexts as well as to the necessary acculturation into the academic discourse of particular disciplines, and that language and academic programs that teach these skills should be embedded in the content being learned.

The context and opportunities for collaborative work of the type we are describing however are in flux, as the vocational education sector undergoes significant change. This is so particularly in Victoria where until recently the Course in Applied Vocational Study Skills (CAVSS) model, which is premised on a literacy teacher being present within the 'classroom' to assist with the literacy and study skills dimensions of the learning being undertaken, provided some scope for the provision of collaborative learning spaces. This option has been largely replaced by the Foundation Skills Training Package, which is designed for delivery by VET teachers rather than language specialists per se, although not without assistance from language specialists where appropriate (Government Skills Australia [GSA] 2014). As Black and Yasukawa (2011) point out however, even CAVSS is premised on an uneven power relationship which limits its effectiveness in terms of enabling genuinely effective collaborative 
relationships, which they stress is important in seeing the relationship between LLN and vocational content as dynamic and contestable (2011). Even within this uneven context however, there remains the possibility of access to different knowledges, and it is this that lies at the heart of the collaborative process.

\section{Conclusion}

Within an already complex and shifting environment, the imperative to take up increased responsibility for LLN has added a significant new dimension to the existing role and identity of VET teachers in Australia. Whilst the need for a broader and more effective approach to LLN support within vocational education is well documented, there has been little if any examination of the responses of VET teachers to this development. This paper has explored the perceptions and understandings of a small group of vocational teachers in relation to these new professional skills and responsibilities. We have argued that whilst there is a willingness on the part of the vocational teachers in this study to take up at least some of the responsibility for language and literacy, the task is not without contradictions and tensions. What is needed, we suggest, is an acknowledgement firstly that the journey is complex and requires time, and secondly that collaborative work with language and literacy specialists is integral to accessing and developing specialist understandings and conceptions of language and literacy itself. Acquiring new specialist knowledge is a potentially dissonant process that involves 'oscillating between previous and emerging understandings' (Wallace 2010:12), and sometimes continuing to perceive oneself as being an imposter in the new space (Brookfield 2000).

We have suggested that the notions of Discourse (Gee 1996), and troublesome knowledge (Land et al 2008) offer a helpful lens onto the nature of the challenge faced by vocational teachers as they grapple with developing understandings of how embedded language and literacy may be conceptualised and enacted in their particular disciplines. An appreciation of language as inherently complex and intimately connected with discipline content, has been put forward as a key threshold concept (Meyer \& Land 2006) that vocational teachers are either implicitly or explicitly grappling with. We have 
proposed a dialogic model, based on a collaborative relationship between vocational teachers and language and literacy support specialists, as one that supports the process that vocational teachers are undergoing as they move towards taking up and incorporating these skills into a new professional practice - into new ways of being and understanding.

\section{Acknowledgements}

The authors would like to thank the anonymous reviewers for their constructive and insightful comments on the earlier version of this paper. We would also like to thank John Hamilton, Jacinta Richards, and Miguel Gil for their generous and helpful feedback on earlier drafts.

\section{References}

Arkoudis, S (2013) ALL at the Crossroads $11^{\text {th }}$, AALL Biennial Conference, Melbourne 14 November, retrieved $13^{\text {th }}$ Nov 2014 from http://www.rmit.edu.au/aall2013.

Australian Industry Group (2010) National Workforce Literacy Project: Report on employers' views on workplace literacy and numeracy skills, retrieved April 2015 from http://www.aigroup.com.au/portal/binary/com.epicentric.conten tmanagement.servlet.ContentDeliveryServlet/LIVE_CONTEN T/Publications/Reports/2010/8783_Workforce_Literacy_Projec t_Report.pdf.

Bak, T and Murphy, H (2009) Reconceiving an Approach to Teaching Legal Discourse: A community of practice project, Journal of the Australasian Law Teachers Association, vol 1, no1 and 2, pp 197-202.

Black, S and Yasukawa, K (2011) Adult Literacy and Numeracy as Social Practices: What does this mean for pedagogy?, 34th ACAL Conference, Literacy on the map: Common visions, different paths, Victoria University, Melbourne 28 September.

Black, S and Yasukawa, K (2013a) Beyond Deficit Models for Integrating Language, Literacy and Numeracy in Australian VET, Journal of Further and Higher Education, vol 37, no 4, pp 574-590. doi:

http://dx.doi.org/10.1080/0309877X.2011.645469 
Black, S and Yasukawa, K (2013b) Disturbing the Pedagogical Status Quo: LLN and vocational teachers working together, Pedagogies: An International Journal, vol 8, no 1, pp 44-59. doi: http://dx.doi.org/10.1080/1554480x.2013.739277

Brookfield, S (2000) Adult cognition as a dimension of lifelong learning, in Field, J, ed, Lifelong learning: Education across the lifespan, Routledge, London.

Casey, H, Cara, O, Eldred, J, Grief, S, Hodge, R, Ivanič, R, Jupp, T, Lopez, D and McNeil, B (2006) "You wouldn't expect a maths teacher to teach plastering ...": Embedding literacy, language and numeracy in post-16 vocational programmes - the impact on learning and achievement, National Research and Development Centre for Adult Literacy and Numeracy, London.

Chappell, C, Scheeres, H and Solomon, N (2007) Working on Identities in Farrell, L and Fenwick, T, eds, World Yearbook of Education 2007: Educating the global workforce: knowledge, knowledge work and knowledge worker, Routlege, NY.

Curró, G (2012) Initiating the Language, Literacy and Numeracy Strategy at Victoria University: A Pilot in the Bachelor of Laws, 2011 AARE Conference, Hobart, retrieved Nov 2014 from http://www.aare.edu.au/11pap/papers_pdf/aarefinal00661.pdf.

Gee, J (1996) Social Linguistics and Literacies: Ideology in discourses, 2nd edition, Taylor and Francis, London.

Government Skills Australia (GSA) (2014) Foundation Skills, retrieved June 2014 from https://www.governmentskills.com.au/foundation-skills.

Hamilton, M and Barton, D (2000) The International Adult Literacy Survey: What does it really measure?, International Review of Education, vol 46, no 5, pp 377-389. Industry Skills Councils (2011) No more excuses: an industry response to the language, literacy and numeracy challenge, Industry Skills Councils, retrieved Feb 2014 from http://www.isc.org.au/pdf/NoMoreExcuses_FINAL\%20single $\% 20$ page.pdf.

Innovation and Business Skills Australia (IBSA) (2012) Changes ahead for VET Trainers and Assessors, retrieved Feb 2014 from https://ibsa.org.au/sites/default/files/downloads/CPTAECHGRPT.pdf. 
Ivanič, R (1998) Language and Identity: The discoursal construction of identity in academic writing, John Benjamins Publishing Company, Amsterdam. doi: http://dx.doi.org/10.1075/swll.5

Ivanič, R, Edwards, R, Barton, D, Martin-Jones, M, Fowler, Z, Hughes, B, Mannion, G, Miller, K, Satchwell, C and Smith, J (2009) Improving Learning in College: Rethinking literacies across the curriculum. Routledge, London.

Jacobs, C (2007) Mainstreaming Academic Literacy Teaching: Implications for how academic development understands its work in higher education, South African Journal of Higher Education, vol 21, no 7, pp 870-881.

Land, R, Meyer, J and Smith, J, Eds, (2008) Threshold Concepts within the disciplines, Sense, Rotterdam.

Lea, M and Street, B (2006) The Academic Literacies Model, Theory into Practice, vol 45, no 4, pp 368-377. doi: http://dx.doi.org/10.1207/s15430421tip4504_11

McCormack, R (2014) Gadamer and ALL: A Hermenuetic Understanding of Academic Language and Learning, Journal of Academic Language and Learning, vol 8, no 3, pp 49-61.

Meyer, J and Land, R, (2003) Threshold Concepts and Troublesome Knowledge: Linkages to ways of thinking and practicing within disciplines, Enhancing Teaching-Learning Environments in Undergraduate Courses Project Occasional Report, retrieved 13 Nov 2014 from http://www.etl.tla.ed.ac.uk/docs/ETLreport4.pdf.

Meyer, J and Land, R, Eds (2006) Overcoming Barriers to Student Understanding: Threshold concepts and troublesome knowledge, Routledge, Abingdon.

Moodie, G and Wheelahan, L (2012) Integration and Fragmentation of Post-compulsory Teacher Education, Journal of Vocational Education and Training, vol 64, no 3, pp 317-31. doi: http://dx.doi.org/10.1080/13636820.2012.691535

Moraitis, P, Carr, A and Daddow, A (2012) Developing and Sustaining New Pedagogies: A case for embedding language, literacy and academic skills in vocational education curriculum, International Journal of Training Research, vol 10, no 1, pp 58-72. doi: http://dx.doi.org/10.5172/ijtr.2012.10.1.58

Murray, N (2010) Conceptualising the English Language Needs of First Year University Students, The International Journal of the 
First Year in Higher Education, vol 1, no 1, pp 55-64. doi: http://dx.doi.org/10.5204/intjfyhe.v1i1.19

Roberts, C, Baynham, M, Shrubshall, P, Brittan, J, Cooper, B, Gidley, N, Windsor, V, Eldred, J, Castillino, C and Walsh, M (2005) Embedded Teaching and Learning of Adult Literacy, Numeracy and ESOL: Seven Case Studies, National Research and Development Centre for Adult Literacy and Numeracy, London.

Rose, M (2012) Rethinking Remedial Education and the AcademicVocational Divide, Mind, Culture, and Activity, vol 19, pp 1-16. doi: http://dx.doi.org/10.1080/10749039.2011.632053

Santoro, N (2003) Caught up in the Teaching-training Divide: Confusing professional identities, Studies in Continuing Education, vol 25, no 2, pp 211-24. doi: http://dx.doi.org/10.1080/0158037032000131538

Seddon, T (2008) Crafting Capacity in VET: Towards an agenda for learning and researching in the VET workforce, Keynote Address to VET in Context, 11th Annual Australian Vocational Education and Training Research Association Conference, Adelaide Holiday Inn Adelaide, 3-4 April.

Skills Australia (2011) Skills for Prosperity: A roadmap for vocational education and training, retrieved April 2015 from http://www.industry.gov.au/skills/Publications/Documents/Skill sProsperityRoadmap-2011.pdf.

Wallace, D (2010) The Grit in the Oyster - does an appreciation of threshold concepts in an adult literacies teaching qualification result in pearls of practice?, Literacy and Numeracy Studies, vol 18, no 1, pp 3-18. doi: http://dx.doi.org/10.5130/lns.v18i1.1426

Wenger, E (1998) Communities of Practice: Learning, meaning, and identity, Cambridge University Press, Cambridge. doi: http://dx.doi.org/10.1017/CBO9780511803932

Wheelahan, L (2009) The Problem with CBT (and why constructivism makes things worse), Journal of Education and Work, vol 22, no 3, pp 227-42. doi: http://dx.doi.org/10.1080/13639080902957913

Wignall, L (1998) Built in not Bolted on: Information kit for Language, literacy and numeracy coordinators on incorporating communication skills into training packages, Australian National Training Authority, Canberra. 